\title{
The role of bariatric surgery in the treatment of diabetes
}

\author{
Ji Chung Tham, Noah Howes and Carel W. le Roux
}

\begin{abstract}
The obesity epidemic contributes to approximately $44 \%$ of the world's type 2 diabetes burden. Bariatric surgery is an effective treatment for type 2 diabetes mellitus in patients with morbid obesity as it improves glycaemia, blood pressure, lipids and inflammation. This review describes the evidence supporting the addition of bariatric surgery to the treatment algorithms used by diabetologists. We emphasize the need to view bariatric surgery as an adjuvant therapy which should not be used instead of but rather together with best medical therapy.
\end{abstract}

Keywords: bariatric surgery, diabetes mellitus, obesity

\section{Introduction}

Epidemiology of diabetes as driven by obesity

Obesity is a growing pandemic responsible for significant health and socioeconomic consequences. Its prevalence has doubled since 1980 with up to 500 million adults being classified as obese in 2008 [WHO, 2011]. Obesity is a result of deranged energy homeostasis which is often the consequence of dysfunction in multiple neuroenteric systems [Pournaras and le Roux, 2009]. Type 2 diabetes (T2DM) rates are increasing alongside obesity with an estimated 170 million people worldwide affected by diabetes mellitus in 2000 [Ginter and Simko, 2010].

Bariatric surgery combined with optimal medical therapy is more effective than a combination of lifestyle and medication interventions for weight loss [Mingrone et al. 2012; Schauer et al. 2012]. Bariatric surgery results in sustained weight loss for up to 20 years, with a reduction in mortality compared with medical care with diets, exercise and medication [Sjöström, 2013; Sjöström et al. 2007]. Further advances in T2DM management must be obtained in order to manage the existing diabetic pandemic and to curb its progress.

This review briefly describes the evidence that supports the addition of bariatric surgery to existing treatment algorithms used by diabetologists.

\section{Surgical technique}

Roux-en-Y gastric bypass

The Roux-en-Y gastric bypass (RYGB) consists of creating a gastric pouch of $20-30 \mathrm{ml}$ in volume that is anastomosed with the distal jejunum. To create this, the jejunum is transected approximately $50 \mathrm{~cm}$ from the duodenojejunal junction [Higa et al. 2000; Welbourn et al. 2010]; the proximal end of the transected jejunum is anastomosed to the distal portion at approximately $100 \mathrm{~cm}$ from the transection point and the distal end to the gastric pouch [Higa et al. 2000]. The newly formed gastrojejunal anastomosis up to the jejunojejunal anastomosis is named the alimentary limb, the gastric remnant to the jejunojejunal anastomosis, the biliopancreatic limb and the remaining portion of the small bowel the common limb. Current accepted configurations are placing the small bowel antecolic or retrocolic with an antegastric reconstruction [Edwards et al. 2007; Müller et al. 2007]. Multiple techniques of performing the gastrojejunal anastomosis have been described with no clear consensus on which is best [Bendewald et al. 2011; Giordano et al. 2011].

\section{Vertical sleeve gastrectomy}

Vertical sleeve gastrectomy (VSG) involves a left partial gastrectomy to leave a thin cylindrical portion of stomach connecting the oesophagus to the pylorus along the lesser curve [ASMBS Clinical Issues Committee, 2012]. Sizing of the sleeve is
Ther Adv Chronic Dis 2014, Vol. 5(3) 149-157 DOI: 10.1177/ 2040622313513313

(c) The Author(s), 2014. Reprints and permissions: http://www.sagepub.co.uk/ journalsPermissions.nav
Correspondence to: Carel W. le Roux, MBChB, MSc, MRCP, FRCPath, PhD Diabetes Complications

Research Centre, UCD

Conway Institute, School of Medicine and Medical Science, University College Dublin, Belfield, Dublin 4. Co. Dublin Ireland, and Gastrosurgical Laboratory, Sahlgrenska Academy, University of Gothenburg Vasagatan 33, 41137 Göteborg. Sweden carel.lerouxlaucd.ie Ji Chung Tham, MBChB, MRCSEd, MSc

General Surgery Department Royal Devon and Exeter Hospital, Exeter, UK jichungthamadoctors. org.uk

Noah Howes, MB BCh Upper Gastrointestinal and Bariatric Surgery Department Musgrove Park Hospital, Taunton, UK noahhowesabristol.ac.uk 
Table 1. Comparison of medical versus LRYGB in weight, glycated haemoglobin and high-density lipoprotein in randomized controlled trials.

\begin{tabular}{|c|c|c|c|c|}
\hline & & Weight (kg) & $\begin{array}{l}\text { Absolute change in postoperative } \\
\text { glycated haemoglobin }(\%)\end{array}$ & High-density lipoprotein* \\
\hline \multirow[t]{2}{*}{ Schauer et al. [2012] } & Medical & $-5.4 \pm 8.0$ & -1.4 & $11.3 \pm 25.7$ \\
\hline & LRYGB & $-29.4 \pm 8.9$ & -2.9 & $28.4 \pm 21.9$ \\
\hline$p$ value & & $<0.001$ & $<0.001$ & 0.001 \\
\hline Mingrone et al. [2012] & Medical & $-4.7 \pm 6.4$ & -0.8 & $6.0 \pm 6.3$ \\
\hline$p$-value & LRYGB & $\begin{array}{c}-33.3 \pm 7.9 \\
<0.001\end{array}$ & $\begin{array}{l}-2.2 \\
0.003\end{array}$ & $\begin{array}{l}29.7 \pm 18.2 \\
0.031\end{array}$ \\
\hline
\end{tabular}

based on a 32-36 French sized bougie, resulting in approximately $100 \mathrm{ml}$ volume [Rosenthal et al. 2012]. It may be performed as a definitive operation or as a stepping stone to a RYGB or a biliopancreatic diversion with or without a duodenal switch.

\section{Adjustable gastric band}

A silicone band is placed around the stomach at the level of the cardia through the pars flaccida [Brown et al. 2008] with an adjustment port placed in the subcutaneous tissue, usually in the epigastric region, connected to the band via silicone tubing. The port contains a silicone diaphragm, which allows repeated punctures with a noncoring needle to alter the volume of the band. The absence of any anatomical changes makes it possible to easily reverse or revise.

\section{Intraluminal gastrointestinal exclusion device}

The use of a device which excludes the duodenum from contact with food in patients with obesity was first described in 2007 [Gersin et al. 2007]. The duodenal-jejunal bypass liner (e.g. Endobarrier, GI Dynamics, Lexington, MA, USA) is placed endoscopically and deployed to cover the proximal $60 \mathrm{~cm}$ of the small bowel. The exclusion of the duodenum results in weight loss and improvement in glycaemia while the device is in place [Escalona et al. 2012]. The device may need to be replaced after 1 year so long-term benefit remains to be quantified. As with the VSG, more long-term data are required to ascertain its value as a standalone procedure.

\section{Surgery as an 'add-on' procedure for diabetes} The first-line treatment for newly diagnosed T2DM is usually lifestyle modification combined with pharmacotherapy. Surgical procedures have only recently been considered as a potential adjunct therapy for T2DM. Yet, we have known about the favourable effects on weight and glycaemia in patients with obesity and T2DM undergoing RYGB since 1978 [Mason et al. 1978]. Moreover in randomized controlled trials, after 2 years, patients who undergo a bariatric surgical procedure compared with medical management maintain better glycated haemoglobin levels and require less medication (Table 1) [Mingrone et al. 2012; Schauer et al. 2012].

In the longer term, blood pressure, glucose and lipids show more favourable results in patients who have had bariatric surgery compared with medical treatment, along with a significant survival improvement [Sjöström et al. 2007]. Although most of the patients who go into early remission of diabetes relapse, there are more patients in T2DM remission in the surgical group after 15 years of follow up [Sjöström, 2013]. Surgery has also been shown to prevent the progression from impaired glucose tolerance to T2DM [Sjöström, 2013], raising the question of whether surgery should also be offered to patients with impaired glucose tolerance and a BMI of less than $40 \mathrm{~kg} / \mathrm{m}^{2}$.

\section{Efficacy of bariatric surgery as a treatment modality for patients with type 2 diabetes mellitus}

\section{Changes in weight}

Weight loss after bariatric surgery is multifactorial. Metabolic, anatomical and lifestyle changes all play important roles; the contribution of each varies from procedure to procedure. For example, in RYGB, there are thought to be at least three 
main mechanisms: speed of transit of food from the oesophagus into the small bowel, gut hormone responses and delayed mixing of bile in the distal small bowel.

RYGB leads to rapid contact of ingested nutrients with the mid gut after a meal stimulating both hormonal responses and the vagus nerve. The neural input to the brain alters meal size and possibly food preference in the postoperative period. Rat models exhibit reduced food intake [Bueter et al. 2010] and an avoidance of high-fat diets [le Roux et al. 2011]. In humans, RYGB results in a selective reduction of the reward value of sweet and fatty tastes [Miras et al. 2012b]. Visual analogue scores showed enhanced postprandial satiation postoperatively, which was associated with exaggerated satiety gut hormone responses [glucagon-like peptide 1 (GLP-1) and peptide tyrosine tyrosine (PYY)] [Borg et al. 2006]. Inhibition of GLP-1 and PYY using the somatostatin analogue octreotide after RYGB increases appetite [le Roux et al. 2007]. The reduction in hunger and increase in satiety coupled with a shift in preference for lower glycaemic index foods are most likely the major factors for long-term sustained weight loss.

Twenty-four hour energy expenditure is paradoxically increased in patients after RYGB compared with patients who have lost the same amount of weight with vertical banded gastroplasty [Werling et al. 2013]. An explanation for the increased energy expenditure and sustained lower body weight in the postoperative period in human and animal models of bypass surgery may be derived from the presence of bile in the ileum rather than duodenum [Pournaras et al. 2012]. Bile plays a role in the regulation of cellular function by modulating nuclear transcription that increases cellular metabolism [Makishima et al. 1999]. This produces an increase in basal metabolic rate, which changes the energy homeostasis, resulting in weight loss. The weight loss as a result of RYGB compared with medical therapy is shown in Table 1.

Gastric banding was initially thought to work through the reduced stomach size above the band [Dixon et al. 2005]. Achieving the optimal intraluminal pressure within the gastric band is key to achieving reduced food intake secondary to attenuated hunger prior to, and increased satiety after, a meal without dysphagia [Burton et al. 2010, 2011]. One mechanism proposed suggested that satiation was felt when food boluses, and not liquids, were squeezed between the gastric band and gastric mucosa [Burton et al. 2010,2011; O'Brien, 2010]. This causes the intraganglionic laminar endings to be stimulated and produce satiety feedback to the brain [O'Brien, 2010], probably through the vagus nerve. The reduction in hunger may also be mediated through the same physiological processes [Dixon et al. 2005]. No gut hormone profile changes occurs after gastric banding, suggesting that resolution of the metabolic syndrome occurs with time as weight is lost [O'Brien, 2010]. Weight loss as a result of gastric band compared with medical therapy is about $15 \%$ [Sjöström, 2013].

The VSG was initially thought to be a restrictive procedure [Yehoshua et al. 2008]. More recent studies have proposed that removal of the fundus may have a hormonal mechanism as it contains ghrelin-producing cells [Goitein et al. 2012; Langer et al. 2005]. Ghrelin levels fall significantly in the postoperative period with permanent attenuation [Peterli et al. 2012]. Patients who have had VSG compared with those with RYGB or gastric band have a more exaggerated fall in ghrelin levels [Peterli et al. 2012; Ramón et al. 2012]. However, the role of ghrelin as a hunger hormone remains unclear as postoperative results are mixed [Goitein et al. 2012; Langer et al. 2005]. Scintigraphy examination post VSG shows that the mechanism of action may be associated with the increased gastrointestinal transit time due to a smaller gastric component resulting in earlier satiety and improved metabolic profile [Shah et al. 2010]. GLP-1 and PYY hormones follow a similar trend to patients who have had RYGB [Jiménez et al. 2012]. The enhanced sensation of satiety may be secondary to this increased gastrointestinal transit, triggering neural signals from the proximal small bowel [Bjorklund et al. 2010] or altering responses of hormones involved with appetite, similar to the RYGB. Patients who have had VSG lose significantly more weight compared with those on optimal medical therapy: weight loss $25.1 \pm 8.5$ compared with $5.4 \pm 8.0$, respectively [Schauer et al. 2012].

Despite their short-term use, the duodenal-jejunal bypass liner is emerging as a potentially interesting procedure with an additional reduction in haemoglobin $\mathrm{A} 1 \mathrm{c}(\mathrm{HbA} 1 \mathrm{c})$ of $1.4 \%$ combined with $10-15 \%$ weight loss at 1 year [Escalona et al. 2012; Schouten et al. 2010]. Since the risk of an endoscopic procedure is lower compared with 
surgery, the duodenal-jejunal bypass liner can be used to focus on patients with T2DM who are not eligible or do not want bariatric surgery. The mechanism of action is yet to be determined [Gersin et al. 2007].

Weight loss maintenance after all the surgical procedures remains a challenge for some patients. The combination of a high-protein and low-glycaemic-index diet with surgery may thus yield better results in the longer term. The role of pharmacotherapy and specifically the addition of GLP-1 analogue therapy to those with suboptimal endogenous GLP-1 [le Roux et al. 2007] appears feasible in rats [Fenske et al. 2013] but needs to be tested in humans.

\section{Changes in glycaemia}

As shown in Table 1, when RYGB is combined with optimal medicine the glycated haemoglobin (HbA1c) improves significantly postoperatively [Mingrone et al. 2012; Schauer et al. 2012]. At 2 years fasting glucose levels were lower in patients who had RYGB compared with those who only received medical therapy [Mingrone et al. 2012]; similar findings have been noted in patients who have had VSG [Schauer et al. 2012]. In patients with T2DM of 2 years or less in duration, more than $70 \%$ of those with a gastric band achieved a fasting blood glucose level of less than $7.0 \mathrm{mmol} /$ liter compared with those receiving medical therapy [Dixon et al. 2008]. At 6 months post implantation of the duodenal-jejunal bypass liner, de Jonge and colleagues demonstrated a mean improvement in $\mathrm{HbAl}$ c from $8.4 \pm 0.2$ to $7.0 \pm$ $0.2 \%$ and fasting glucose improved from $11.6 \pm$ 0.5 to $8.6 \pm 0.5 \mathrm{mmol} /$ liter [de Jonge et al. 2013]. In an observational study by de Moura and colleagues, at 1-year follow up, $72.7 \%$ of patients with endoscopic duodenal-jejunal bypass liner had an improvement in their T2DM [de Moura et al. 2012]. The exclusion of the duodenum from contact with nutrients appears to have a profound metabolic effect that is yet to be fully understood. It is likely to have a similar mechanism of action as the duodenal-jejunal bypass surgical procedure performed on animal models [Breen et al. 2012] or indeed the biliopancreatic limb of the RYGB. Combining surgery with metformin appears to have very few problems and given the proven advantages of metformin as regards longterm morbidity and mortality, clinicians should think carefully before discontinuing the drug after surgery.
Changes in hepatic insulin resistance and peripheral insulin resistance

Serum bile acid levels are increased and maintained in the postoperative state after RYGB, and are associated with improvements in glucose profiles [Makishima et al. 1999; Nakatani et al. 2009; Patti et al. 2009]. Bile also improves glycaemia by stimulating incretin hormones GLP-1 and PYY [Pournaras et al. 2012]. Additionally, RYGB leads to rapid contact of ingested nutrients with jejunal mucosa after a meal, which may stimulate mechanoreceptors. Rapid direct contact of long-chain fatty acid (LCFA) with bowel mucosa stimulates incretin responses via a neuroenteric circuit [Wang et al. 2008]. LCFA trigger impulses via the vagus to the hindbrain, which then produce a feedback impulse to the liver. Vagal stimulation may also increase incretin secretion and reduces endogenous glucose production by the liver [Wang et al. 2008]. Animal models with the duodenal-jejunal bypass surgery confirmed the presence of jejunal nutrient sensing and its incretin effect in normalizing serum glucose levels [Breen et al. 2012]. Breen and colleagues also found that infusing glucose directly into the jejunum produced a similar effect to LCFA [Breen et al. 2012], likely to also involve the vagus nerve.

In VSG, insulin sensitivity improves, but to a lesser degree than in RYGB [Kashyap et al. 2013]. After RYGB, hepatic insulin resistance improves with increased insulin-stimulated glucose uptake [Promintzer-Schifferl et al. 2011]. In rodent models with VSG, Zucker diabetic fatty rats had significantly lower serum glucose levels over time compared with controls, suggesting decreased insulin resistance [Kadera et al. 2013].

In the use of duodenal-jejunal bypass liners, improved insulin sensitivity can be observed as early as 1 week postoperatively without change in insulin levels [de Jonge et al. 2013]. The speed of change in insulin resistance suggests that weight loss or calorie restriction may not be causal, especially as increased insulin resistance is the norm in patients on medical therapy or those who are calorie restricted.

\section{Changes in insulin secretion}

At 2 years, pancreatic $\beta$-cell function improves in patients with RYGB but not in those who have had VSG [Kashyap et al. 2013]. Postoperatively, plasma concentration levels of insulin are reduced but the postprandial response is exaggerated 
[Promintzer-Schifferl et al. 2011]. These changes occur within days of the procedure and are associated with a rise in GLP-1 [Pournaras et al. 2010]. Similar observations are seen in VSG with a rise in GLP-1, PYY, reduced fasting insulin levels and increased insulin sensitivity [Papamargaritis et al. 2013], but to a lesser extent than in RYGB. These differences may account for the superior glycaemic control in patients with RYGB.

In patients with a gastric band, no significant incretin or gut hormone changes occur [Pournaras et al. 2010]. Improvement in glycaemia, insulin secretion and insulin resistance is directly related to weight loss for this cohort. With regular and careful follow up, similar improvements in T2DM control with gastric banding and RYGB can be obtained [O'Brien and Dixon, 2003]. However, when comparing gastric banding and RYGB, improvements in T2DM are more marked in the latter [Buchwald et al. 2004].

In patients with longstanding T2DM who may require increasing doses of exogenous insulin, surgery may allow the patient to come off all insulin or facilitate a significant dose reduction and simplification of the regimen from basal bolus to only requiring once daily insulin analogue therapy [Fenske et al. 2012].

\section{Changes in blood pressure}

Blood pressure improves in $73.2 \%$ of patients who are still losing weight after bariatric surgery, with Vest and colleagues showing a mean reduction of blood pressure from 140.2/87.6 to $129.6 / 80.2 \mathrm{mmHg}$ [Vest et al. 2012]. When comparing gastric band with RYGB, Buchwald demonstrated an improvement in $71.5 \%$ compared with $87.1 \%$ during or immediately after weight loss [Buchwald et al. 2004]. In a separate metaanalysis by Sarkhosh and colleagues, improvements in blood pressure were seen in $75 \%$ of patients who had VSG whilst they were in a negative energy balance [Sarkhosh et al. 2012]. A similar improvement in blood pressure is seen with the duodenal-jejunal bypass liner [Escalona et al. 2012]. However, blood pressure may often increase back to preoperative levels even if weight loss is maintained [Sjöström, 2004]. The mechanisms for improved blood pressure are multifactorial and may be associated with weight loss, reduced systemic inflammation, increased urinary sodium loss and restoration of metabolic homeostasis. Operations such as the RYGB may have additional urinary sodium excretion effects, which may result in longer-term superior blood pressure improvements compared with gastric banding [Hallersund et al. 2012]. It is common for drugs such as angiotensin-converting enzyme inhibitors (ACEis) to be stopped after surgery. This may not be as helpful as just reducing the dose and combining it with surgery in order for resistant hypertension to be addressed. Low doses of ACEi also appear to have benefits beyond the blood pressure reduction effect [Yusuf et al. 2000].

\section{Changes in lipid profile}

Following surgery, serum total cholesterol, triglycerides and low-density lipid (LDL) decrease while high-density lipid increases [Vest et al. 2012]. Taken together with improvements in $\mathrm{T} 2 \mathrm{DM}$ and blood pressure, the Framingham risk score for cardiac events improves [Vest et al. 2012]. Serum total cholesterol and triglycerides improve in patients with gastric band and RYGB [Buchwald et al. 2004]. In a small study comparing VSG and RYGB, there was a significant reduction in total cholesterol and LDL cholesterol at 1 year for patients who had RYGB but not VSG [Vix et al. 2012]. The initial changes in lipid profile seen in patients who had RYGB and not VSG may be due to changes in serum bile levels causing the alteration of cholesterol metabolism via modulation of nuclear transcription [Makishima et al. 1999]. Similar improvement in lipid profile is seen with the duodenal-jejunal bypass liner; however, the mechanism of action is not yet well understood [Escalona et al. 2012]. Although surgery often improves the lipid profile there is no clear rationale for stopping statins in patients with T2DM, especially as the effects of statins can be potentiated by surgery, thus resulting in much improved lipid profiles that may even result in a reversal of atherosclerotic plaque [Puri et al. 2013].

\section{Changes in inflammation and changes in end- organ damage}

The metabolic syndrome is partly driven by inflammation, which in turn is associated with end-organ damage. As patients lose weight after bariatric surgery, improvements in insulin resistance appear to correlate with improved C-reactive protein and tumour necrosis factor $\alpha$ [Kopp et al. 2003]. At 1-year follow up after bariatric surgery, serum inflammatory markers improve with reduction in 
urinary and serum cytokine levels along with improved serum cystatin C levels, indicating improved renal function [Fenske et al. 2013]. In other studies, marked improvements in urinary sodium excretion [Hallersund et al. 2012] and a reduction in urinary markers of renal inflammation occur [Patle et al. 2012], suggesting the presence of a gut-renal axis controlling excretory function and regulating inflammation.

The development of T2DM in patients with a high percentage of body fat is often related to chronic low-grade inflammation in visceral fat [Brunetti, 2007]. Patients who develop metabolic syndrome show more low-grade chronic inflammation in their visceral adipose tissue compared with those that do not [Gauthier and Ruderman, 2010]. The oxidative stress that results from this inflammation contributes to cellular dysfunction in $\beta$-islet cells and endothelial cells.

T2DM is a systemic disease and the subsequent end-organ damage is the major cause of morbidity and mortality. Diabetic kidney disease is a result of microvascular damage to the renal glomeruli and appears for most parts to be progressive. After bariatric surgery, an improvement in kidney damage can be demonstrated with improved microalbuminuria [Miras et al. 2012a] and albuminuria [Iaconelli et al. 2011]. Halting the process of endorgan damage is vital in treating diabetes.

\section{Combining medicine and surgery}

It seems that the higher the risk of bariatric surgical procedures, the greater the improvement in comorbidities [Buchwald et al. 2004; Sjöström et al. 2007]. RYGB has fewer risks than biliopancreatic diversion and is thought to have better weight loss and metabolic improvements than adjustable gastric banding. It is hoped that newer less invasive procedures such as the duodenaljejunal liners may help those patients with T2DM who are either not fit enough for bariatric surgery or who do not want bariatric surgery. Additionally, preoperative optimization with best medical treatment may result in better postoperative outcome [Frisch et al. 2010]. Currently, surgery is often proposed instead of current optimal medicine, but a subtle shift to promote surgery as adjunct therapy together with medical therapy may yield far superior results than the two modalities alone. Unsurprising, a multimodal approach to treating T2DM yields better results [Gaede et al. 2003]. Surgery as an add-on therapy to existing medicine could therefore be considered to be the optimal treatment for patients with T2DM and morbid obesity.

\section{Funding}

This research received no specific grant from any funding agency in the public, commercial, or notfor-profit sectors.

\section{Conflict of interest statement}

The authors declare no conflicts of interest in preparing this article.

\section{References}

ASMBS Clinical Issues Committee (2012) Updated position statement on sleeve gastrectomy as a bariatric procedure. Surg Obes Relat Dis 8: e21-e26.

Bendewald, F., Choi, J., Blythe, L., Selzer, D., Ditslear, J. and Mattar, S. (2011) Comparison of hand-sewn, linear-stapled, and circular-stapled gastrojejunostomy in laparoscopic Roux-en-Y gastric bypass. Obes Surg 21: 1671-1675.

Bjorklund, P., Laurenius, A., Een, E., Olbers, T., Lonroth, H. and Fandriks, L. (2010) Is the Roux limb a determinant for meal size after gastric bypass surgery? Obes Surg 20: 1408-1414.

Borg, C., le Roux, C., Ghatei, M., Bloom, S., Patel, A. and Aylwin, S. (2006) Progressive rise in gut hormone levels after Roux-en-Y gastric bypass suggests gut adaptation and explains altered satiety. Brf Surg 93: 210-215.

Breen, D., Rasmussen, B., Kokorovic, A., Wang, R., Cheung, G. and Lam, T. (2012) Jejunal nutrient sensing is required for duodenal-jejunal bypass surgery to rapidly lower glucose concentrations in uncontrolled diabetes. Nat Med 18: 950-955.

Brown, W., Burton, P., Anderson, M., Korin, A., Dixon, J., Hebbard, G. et al. (2008) Symmetrical pouch dilatation after laparoscopic adjustable gastric banding: incidence and management. Obes Surg 18: 1104-1108.

Brunetti, P. (2007) The lean patient with type 2 diabetes: characteristics and therapy challenge. Int f Clin Pract Suppl 61: 1776.

Buchwald, H., Avidor, Y., Braunwald, E., Jensen, M., Pories, W., Fahrbach, K. et al. (2004) Bariatric surgery: a systematic review and meta-analysis. $\mathcal{F} A M A$ 292: 1724-1737.

Bueter, M., Lowenstein, C., Olbers, T., Wang, M., Cluny, N., Bloom, S. et al. (2010) Gastric bypass increases energy expenditure in rats. Gastroenterology 138: 1845-1853. 
Burton, P., Yap, K., Brown, W., Laurie, C., O'Donnell, M., Hebbard, G. et al. (2010) Effects of adjustable gastric bands on gastric emptying, supraand infraband transit and satiety: a randomized double-blind crossover trial using a new technique of band visualization. Obes Surg 20: 1690-1697.

Burton, P., Yap, K., Brown, W., Laurie, C., O'Donnell, M., Hebbard, G. et al. (2011) Changes in satiety, supra- and infraband transit, and gastric emptying following laparoscopic adjustable gastric banding: a prospective follow-up study. Obes Surg 21: 217-223.

de Jonge, C., Rensen, S., Verdam, F., Vincent, R., Bloom, S., Buurman, W. et al. (2013) Endoscopic duodenal-jejunal bypass liner rapidly improves type 2 diabetes. Obes Surg 23: 1354-1360.

de Moura, E., Martins, B., Lopes, G., Orso, I., de Oliveira, S., Galvão Neto, M. et al. (2012) Metabolic improvements in obese type 2 diabetes subjects implanted for 1 year with an endoscopically deployed duodenal-jejunal bypass liner. Diabetes Technol Ther 14: 183-189.

Dixon, A., Dixon, J. and O'Brien, P. (2005) Laparoscopic adjustable gastric banding induces prolonged satiety: a randomized blind crossover study. f Clin Endocrinol Metab 90: 813-819.

Dixon, J., O’Brien, P., Playfair, J., Chapman, L., Schachter, L., Skinner, S. et al. (2008) Adjustable gastric banding and conventional therapy for type 2 diabetes: a randomized controlled trial. $\mathcal{F} A M A 299$ : 316-323.

Edwards, M., Jones, D., Ellsmere, J., Grinbaum, R. and Schneider, B. (2007) Anastomotic leak following antecolic versus retrocolic laparoscopic Roux-en-Y gastric bypass for morbid obesity. Obes Surg 17: 292-297.

Escalona, A., Pimentel, F., Sharp, A., Becerra, P., Slako, M., Turiel, D. et al. (2012) Weight loss and metabolic improvement in morbidly obese subjects implanted for 1 year with an endoscopic duodenaljejunal bypass liner. Ann Surg 255: 1080-1085.

Fenske, W., Bueter, M., Miras, A., Ghatei, M., Bloom, S. and le Roux, C. (2012) Exogenous peptide YY3-36 and Exendin-4 further decrease food intake, whereas octreotide increases food intake in rats after Roux-en-Y gastric bypass. Int $\mathcal{F}$ Obes (Lond) 36: 379-384.

Fenske, W., Dubb, S., Bueter, M., Seyfried, F., Patel, K., Tam, F. et al. (2013) Effect of bariatric surgery-induced weight loss on renal and systemic inflammation and blood pressure: a 12-month prospective study. Surg Obes Relat Dis 9: 559-568.

Frisch, A., Chandra, P., Smiley, D., Peng, L., Rizzo, M., Gatcliffe, C. et al. (2010) Prevalence and clinical outcome of hyperglycemia in the perioperative period in noncardiac surgery. Diabetes Care 33: 1783-1788.

Gaede, P., Vedel, P., Larsen, N., Jensen, G., Parving, H. and Pedersen, O. (2003) Multifactorial intervention and cardiovascular disease in patients with type 2 diabetes. N Engl F Med 348: 383-393.

Gauthier, M. and Ruderman, N. (2010) Adipose tissue inflammation and insulin resistance: all obese humans are not created equal. Biochem f 430: e1-e4.

Gersin, K., Keller, J., Stefanidis, D., Simms, C., Abraham, D., Deal, S. et al. (2007) Duodenaljejunal bypass sleeve: a totally endoscopic device for the treatment of morbid obesity. Surg Innov 14: 275-278.

Ginter, E. and Simko, V. (2010) Diabetes type 2 pandemic in 21st century. Bratisl Lek Listy 111 : 134-137.

Giordano, S., Salminen, P., Biancari, F. and Victorzon, M. (2011) Linear stapler technique may be safer than circular in gastrojejunal anastomosis for laparoscopic Roux-en-Y gastric bypass: a metaanalysis of comparative studies. Obes Surg 21: 1958-1964.

Goitein, D., Lederfein, D., Tzioni, R., Berkenstadt, H., Venturero, M. and Rubin, M. (2012) Mapping of ghrelin gene expression and cell distribution in the stomach of morbidly obese patients-a possible guide for efficient sleeve gastrectomy construction. Obes Surg 22: 617-622.

Hallersund, P., Sjöström, L., Olbers, T., Lönroth, H., Jacobson, P., Wallenius, V. et al. (2012) Gastric bypass surgery is followed by lowered blood pressure and increased diuresis - long term results from the Swedish Obese Subjects (SOS) study. PLoS One 7: e49696.

Higa, K., Boone, K., Ho, T. and Davies, O. (2000) Laparoscopic Roux-en-Y gastric bypass for morbid obesity: technique and preliminary results of our first 400 patients. Arch Surg 135: 1029-1033; discussion 1033-1034.

Iaconelli, A., Panunzi, S., De Gaetano, A., Manco, M., Guidone, C., Leccesi, L. et al. (2011) Effects of bilio-pancreatic diversion on diabetic complications: a 10-year follow-up. Diabetes Care 34: 561-567.

Jiménez, A., Casamitjana, R., Flores, L., Viaplana, J., Corcelles, R., Lacy, A. et al. (2012) Long-term effects of sleeve gastrectomy and Roux-en-Y gastric bypass surgery on type 2 diabetes mellitus in morbidly obese subjects. Ann Surg 256: 1023-1029.

Kadera, B., Portenier, D., Yurcisin, B., Demaria, E., Gaddor, M. and Jain-Spangler, K. (2013) Evidence for a metabolic mechanism in the improvement of type 2 diabetes after sleeve gastrectomy in a rodent model. Surg Obes Relat Dis 9: 447-452. 
Kashyap, S., Bhatt, D., Wolski, K., Watanabe, R., Abdul-Ghani, M., Abood, B. et al. (2013) Metabolic effects of bariatric surgery in patients with moderate obesity and type 2 diabetes: analysis of a randomized control trial comparing surgery with intensive medical treatment. Diabetes Care 36: 2175-2182.

Kopp, H., Kopp, C., Festa, A., Krzyzanowska, K., Kriwanek, S., Minar, E. et al. (2003) Impact of weight loss on inflammatory proteins and their association with the insulin resistance syndrome in morbidly obese patients. Arterioscler Thromb Vasc Biol 23: 1042-1047.

Langer, F., Reza Hoda, M., Bohdjalian, A., Felberbauer, F., Zacherl, J., Wenzl, E. et al. (2005) Sleeve gastrectomy and gastric banding: effects on plasma ghrelin levels. Obes Surg 15: 1024-1029.

le Roux, C., Bueter, M., Theis, N., Werling, M., Ashrafian, H., Löwenstein, C. et al. (2011) Gastric bypass reduces fat intake and preference. Am F Physiol Regul Integr Comp Physiol 301: R1057-R1066.

le Roux, C., Welbourn, R., Werling, M., Osborne, A., Kokkinos, A., Laurenius, A. et al. (2007) Gut hormones as mediators of appetite and weight loss after Roux-en-Y gastric bypass. Ann Surg 246: 780-785.

Makishima, M., Okamoto, A., Repa, J., Tu, H., Learned, R., Luk, A. et al. (1999) Identification of a nuclear receptor for bile acids. Science 284: 1362-1365.

Mason, E., Printen, K., Blommers, T. and Scott, D. (1978) Gastric bypass for obesity after ten years experience. Int $\mathcal{F}$ Obes 2: 197-206.

Mingrone, G., Panunzi, S., De Gaetano, A., Guidone, C., Iaconelli, A., Leccesi, L. et al. (2012) Bariatric surgery versus conventional medical therapy for type 2 diabetes. $N$ Engl f Med 366: 1577-1585.

Miras, A., Chuah, L., Lascaratos, G., Faruq, S., Mohite, A., Shah, P. et al. (2012a) Bariatric surgery does not exacerbate and may be beneficial for the microvascular complications of type 2 diabetes. Diabetes Care 35: e81.

Miras, A., Jackson, R., Jackson, S., Goldstone, A., Olbers, T., Hackenberg, T. et al. (2012b) Gastric bypass surgery for obesity decreases the reward value of a sweet-fat stimulus as assessed in a progressive ratio task. Am f Clin Nutr 96: 467-473.

Müller, M., Guber, J., Wildi, S., Guber, I., Clavien, P. and Weber, M. (2007) Three-year follow-up study of retrocolic versus antecolic laparoscopic Roux-en-Y gastric bypass. Obes Surg 17: 889-893.

Nakatani, H., Kasama, K., Oshiro, T., Watanabe, M., Hirose, H. and Itoh, H. (2009) Serum bile acid along with plasma incretins and serum high-molecular weight adiponectin levels are increased after bariatric surgery. Metabolism 58: 1400-1407.

O'Brien, P. (2010) Bariatric surgery: mechanisms, indications and outcomes. F Gastroenterol Hepatol 25: 1358-1365.

O'Brien, P. and Dixon, J. (2003) Lap-band: outcomes and results. F Laparoendosc Adv Surg Tech A 13: 265-270.

Papamargaritis, D., le Roux, C., Sioka, E., Koukoulis, G., Tzovaras, G. and Zacharoulis, D. (2013) Changes in gut hormone profile and glucose homeostasis after laparoscopic sleeve gastrectomy. Surg Obes Relat Dis 9: 192-201.

Patle, R., Dubb, S., Alaghband-Zadeh, J., Sherwood, R., Tam, F., Frankel, A. et al. (2012) Improved blood pressure, nitric oxide and asymmetric dimethylarginine are independent after bariatric surgery. Ann Clin Biochem 49: 589-594.

Patti, M., Houten, S., Bianco, A., Bernier, R., Larsen, P., Holst, J. et al. (2009) Serum bile acids are higher in humans with prior gastric bypass: potential contribution to improved glucose and lipid metabolism. Obesity (Silver Spring) 17: 1671-1677.

Peterli, R., Steinert, R., Woelnerhanssen, B., Peters, T., Christoffel-Courtin, C., Gass, M. et al. (2012) Metabolic and hormonal changes after laparoscopic Roux-en-Y gastric bypass and sleeve gastrectomy: a randomized, prospective trial. Obes Surg 22: 740-748.

Pournaras, D., Glicksman, C., Vincent, R., Kuganolipava, S., Alaghband-Zadeh, J., Mahon, D. et al. (2012) The role of bile after Roux-en-Y gastric bypass in promoting weight loss and improving glycaemic control. Endocrinology 153: 3613-3619.

Pournaras, D. and le Roux, C. (2009) Obesity, gut hormones, and bariatric surgery. World F Surg 33: 1983-1988.

Pournaras, D., Osborne, A., Hawkins, S., Vincent, R., Mahon, D., Ewings, P. et al. (2010) Remission of type 2 diabetes after gastric bypass and banding: mechanisms and 2 year outcomes. Ann Surg 252: 966-971.

Promintzer-Schifferl, M., Prager, G., Anderwald, C., Mandl, M., Esterbauer, H., Shakeri-Leidenmühler, S. et al. (2011) Effects of gastric bypass surgery on insulin resistance and insulin secretion in nondiabetic obese patients. Obesity (Silver Spring) 19: 1420-1426.

Puri, R., Nissen, S., Ballantyne, C., Barter, P., Chapman, M., Erbel, R. et al. (2013) Factors underlying regression of coronary atheroma with potent statin therapy. Eur Heart f 34: 1818-1825.

Ramón, J., Salvans, S., Crous, X., Puig, S., Goday, A., Benaiges, D. et al. (2012) Effect of Roux-en-Y gastric bypass vs sleeve gastrectomy on glucose and 
gut hormones: a prospective randomised trial. f Gastrointest Surg 16: 1116-1122.

Rosenthal, R., Diaz, A., Arvidsson, D., Baker, R., Basso, N., Bellanger, D. et al. (2012) International Sleeve Gastrectomy Expert Panel Consensus Statement: best practice guidelines based on experience of $>12,000$ cases. Surg Obes Relat Dis 8: 8-19.

Sarkhosh, K., Birch, D., Shi, X., Gill, R. and Karmali, S. (2012) The impact of sleeve gastrectomy on hypertension: a systematic review. Obes Surg 22: 832-837.

Schauer, P., Kashyap, S., Wolski, K., Brethauer, S., Kirwan, J., Pothier, C. et al. (2012) Bariatric surgery versus intensive medical therapy in obese patients with diabetes. N Engl F Med 366: 1567-1576.

Schouten, R., Rijs, C., Bouvy, N., Hameeteman, W., Koek, G., Janssen, I. et al. (2010) A multicenter, randomized efficacy study of the EndoBarrier Gastrointestinal Liner for presurgical weight loss prior to bariatric surgery. Ann Surg 251: 236-243.

Shah, S., Shah, P., Todkar, J., Gagner, M., Sonar, S. and Solav, S. (2010) Prospective controlled study of effect of laparoscopic sleeve gastrectomy on small bowel transit time and gastric emptying half-time in morbidly obese patients with type 2 diabetes mellitus. Surg Obes Relat Dis 6: 152-157.

Sjöström, L. (2013) Review of the key results from the Swedish Obese Subjects (SOS) trial - a prospective controlled intervention study of bariatric surgery. F Intern Med 273: 219-234.

Sjöström, L., Narbro, K., Sjöström, C., Karason, K., Larsson, B., Wedel, H. et al. (2007) Effects of bariatric surgery on mortality in Swedish obese subjects. N Engl f Med 357: 741-752.

Sjöström L., Lindroos AK, Peltonen M., Torgerson J., Bouchard C., Carlsson B. et al. (2004) Lifestyle, diabetes, and cardiovascular risk factors 10 years after bariatric surgery. $N$ Engl F Med, 351: 2683-93.

Vest, A., Heneghan, H., Agarwal, S., Schauer, P. and Young, J. (2012) Bariatric surgery and cardiovascular outcomes: a systematic review. Heart 98: 1763-1777.

Vix, M., Diana, M., Liu, K., D’Urso, A., Mutter, D., Wu, H. et al. (2012) Evolution of glycolipid profile after sleeve gastrectomy vs. Roux-en-Y gastric bypass: results of a prospective randomized clinical trial. Obes Surg 23: 613-621.

Wang, P., Caspi, L., Lam, C., Chari, M., Li, X., Light, P. et al. (2008) Upper intestinal lipids trigger a gut-brain-liver axis to regulate glucose production. Nature 452: 1012-1016.

Welbourn, R., Fiennes, A., Kinsman, R. and Walton, P. (2010) National Bariatric Surgery Registry: first registry report to March 2010. Henley on Thames, UK: Dendrite Clinical Systems Ltd.

Werling, M., Olbers, T., Fändriks, L., Bueter, M., Lönroth, H., Stenlöf, K. et al. (2013) Increased postprandial energy expenditure may explain superior long term weight loss after Roux-en-Y gastric bypass compared to vertical banded gastroplasty. PLoS One 8: e60280.

WHO (2011) Obesity and overweight. Available at: http://www.who.int/mediacentre/factsheets/fs311/en/ index.html (accessed 6 November 2013).

Yehoshua, R., Eidelman, L., Stein, M., Fichman, S., Mazor, A., Chen, J. et al. (2008) Laparoscopic sleeve gastrectomy - volume and pressure assessment. Obes Surg 18: 1083-1088.

Yusuf, S., Sleight, P., Pogue, J., Bosch, J., Davies, R. and Dagenais, G. (2000) Effects of an angiotensin-converting-enzyme inhibitor, ramipril, on cardiovascular events in high-risk patients. The Heart Outcomes Prevention Evaluation Study Investigators. N Engl F Med 342: 145-153.
Visit SAGE journals online http://taj.sagepub.com

(SAGE journals 